\title{
HAEMOPOIESIS AND SIDEROSIS IN THE FOETUS AND NEWBORN
}

\author{
BY \\ F. A. LANGLEY \\ From the Departments of Obstetrics and Gynaecology and of Pathology, Manchester University
}

(Received for Plblication March 8, 1950)

In 1941 Gilmour described haemopoiesis in the foetus and newly born infant. His investigations were primarily qualitative and were undertaken as a preliminary to the study of erythroblastosis foetalis (1944). The investigations to be reported here were essentially quantitative. Their ultimate objective was the comparison of the amounts of haemopoietic tissue and stainable free iron in the organs of newborn infants dying of haemolytic disease with those of a control group of infants dying from other causes. The observations on the control group of infants seemed so interesting and the conclusions so important that they are reported here in detail.

It is shown below that recession of hepatic haemopoiesis is of two types: a foetal type occurring mainly in the last few weeks of intra-uterine life and an infantile type which follows approximately a logarithmic law. The mechanisms concerned in these two types are probably different. The postnatal fall in the erythrocyte count is due, at least in part, to the decline in extramedullary erythrocyte production rather than mainly to excessive breakdown of red cells. The rate of fall of the red cell count depends, therefore, on the rate of recession of extramedullary haemopoiesis before and after birth and on the mean life span of the cells. Free iron was found in the livers of half the stillborn infants examined; this corresponds to the high but variable iron content of the foetal liver reported by Ramage, Sheldon, and Sheldon (1933), and by McDougall (1946). It suggests that this is a store of iron available for hepatic haemopoiesis. After birth hepatic siderosis increased in frequency and amount as extramedullary haemopoiesis diminished, which might be expected with a reduced local utilization of iron.

On examining the results of previous workers with regard to (1) the time of the greatest fall in the red cell count (Findlay, Higgins, and Stanier, 1947); (2) the occurrence of physiological icterus (Davidson, Merritt, and Weech, 1941; Findlay et al., 1947);
(3) experimental bilirubinaemia following life at low oxygen tensions (Goldbloom and Gottlieb. 1930); and (4) hepatic siderosis (Brückmann and Zondek, 1939), it is evident that the theory of excessive haemolysis after birth as the cause of the postnatal fall in the red cell count is inadequate. Thus the way is opened for a reconsideration of the changes in the haemopoietic system at birth.

\section{Material and Methods}

Selection of Material. The livers, spleens and kidneys of 18 stillborn and 74 live born infants were examined. The live born infants died at ages ranging from 10 minutes to 7 months. Forty-eight infants were premature and 44 full term. The material was drawn from a pool of about 1,000 infant necropsies performed by myself. The selection was not random but drawn so as to resemble the series of cases of haemolytic disease with regard to the size of the various age groups and the degree of maturity. Since all these infants were dead they did not constitute a group of strictly normal controls, an unavoidable limitation in this kind of investigation. Almost all the premature infants of 3 days of age or less died as a result of intracranial birth injury, asphyxia. or atelectasis; after three days infection caused the majority of deaths. In the full term infants intracranial birth injury, asphyxia, or atelectasis accounted for most of the deaths in the first week of life, after which infection was the principal cause of death. I have, perforce, assumed that these lesions caused no significant general change in haemopoiesis or iron metabolism in this group of infants, although some change may have occurred in individual cases. Since the pool was collected over the years 1941 to 1948 no systematic investigation of the $\mathrm{Rh}$ factor had been made on most of the infants. There was no clinical or pathological evidence that any of these infants had haemolytic disease of the newly born, although in two cases subsequent sibs were affected.

The degree of prematurity was determined principally by the menstrual history of the mother. In the analysis which follows crown-heel length was sometimes used as a second criterion. These measures were used in preference to body weight, since in this analysis the emphasis was on anatomical maturity rather than on functional capacity, which clinically is so important. Moreover in 


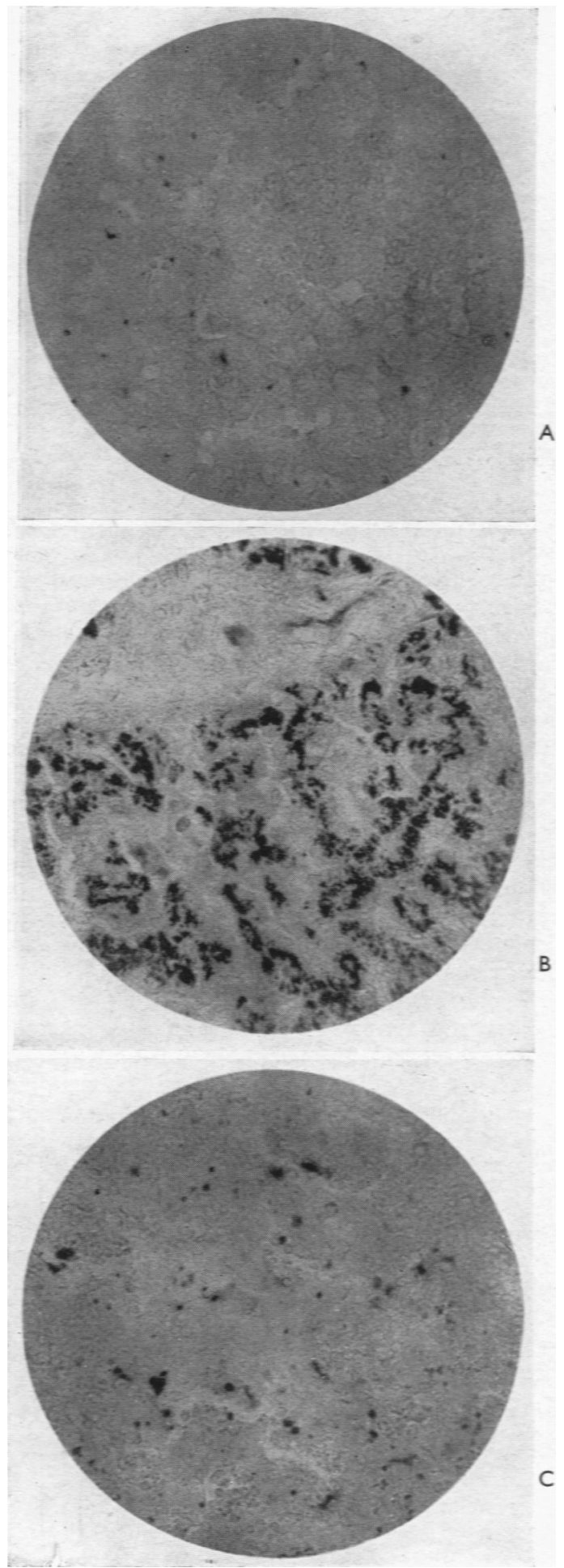

haemolytic disease the body weight may be increased by oedema. The assessment of prematurity is discussed by Potter and Adair (1940), and the procedure adopted here is in line with their findings.

Technique. Sections of the liver, spleen, and kidney were stained by Mayer's haemalum and eosin and Gömöri's iron stain (1936). For the iron reaction watery eosin was used as a light counter stain for the purpose of contrast. Occasionally carmalum was also used but this produced a picture too full of detail for estimating the amount of iron present. Sections of the liver and spleen were also stained by Van Gieson's method and by Gömöri's (1937) silver method for reticulin.

Hepatic haemopoiesis was measured by counting the number of foci of haemopoiesis in a hundred microscopic fields ( $\times 275$ ) and taking the mean. When the foci were few they were usually small and discrete; when numerous they were usually larger and more confluent making it difficult to count them accurately. Siderosis was estimated by examining a hundred fields $(\times 275)$, and if no iron was seen a score of zero was given; if a very little iron, a score of one; if the field was packed with iron to saturation a score of three; intermediate amounts were scored two. Fig. 1 illustrates this method of scoring. The number of fields for each score was thus found and the result expressed: for example, 0, 5, 75, 20, the score being in ascending order $(0,1,2,3)$ from left to right. The cases were then ranked according to their score formulae. Thus A, with a formula $20,60,20,0$, evidently contained less iron than B with a formula $\mathrm{C}, 5$, 75,20 . When formulae were so similar that no certain difference could be made (e.g., $0,7,72,21$, and $0,5,75$, 20) they were given the same grade. It was found possible to divide the livers into 21 grades and the spleens into twelve.

\section{Amalysis of Results}

Intra-uterine Recession. In Table 1 the number of haemopoietic foci present in the liver of stillborn premature infants is compared with the number found in stillborn full term infants. Whatever the criterion of prematurity, menstrual age, crown-heel length or both, the mean number of haemopoietic foci in premature infants exceeded that of full term infants. (When prematurity was determined by menstrual age alone or by both criteria taken together the difference was significant. When crown-heel length was used alone the difference was suggestive but not significant. When both criteria were used three infants were omitted since each was

(A) Iron visible as black dots in a few cells, score 1.

(B) Iron present in large amounts in almost all parenchymal cells, score 3. The iron-free patch corresponds to a small portal tract. From full term infant aged 3 days.

(C) Iron present in some liver cells, intermediate in amount between that seen in $(A)$ and $(B)$, thus score 2 .

FKG. 1.-Three sections of liver showing the method of grading the visible iron content. The iron is stained by the Prussian-blue method; the rest of the tissue is stained lightly with eosin. Magnification $\times 275$. 
TABLE 1

Comparison of Hepatic haemopoiesis in Stillborn Infants born Prematurely and at full Term

\begin{tabular}{|c|c|c|c|c|c|c|c|}
\hline & & \multicolumn{2}{|c|}{$\begin{array}{c}\text { Comparison by Menstrual } \\
\text { Age }\end{array}$} & \multicolumn{2}{|c|}{$\begin{array}{l}\text { Comparison by Crown-Heel } \\
\text { Length* }\end{array}$} & \multicolumn{2}{|c|}{$\begin{array}{l}\text { Comparison by both } \\
\text { Criteria }\end{array}$} \\
\hline & & $\begin{array}{l}\text { No. of } \\
\text { Infants }\end{array}$ & $\begin{array}{l}\text { No. of Foci of } \\
\text { Haemopoiesis }\end{array}$ & $\begin{array}{l}\text { No. of } \\
\text { Infants }\end{array}$ & $\begin{array}{l}\text { No. of Foci of } \\
\text { Haemopoiesis }\end{array}$ & $\begin{array}{l}\text { No. of } \\
\text { Infants }\end{array}$ & $\begin{array}{l}\text { No. of Foci of } \\
\text { Haemopoiesis }\end{array}$ \\
\hline $\begin{array}{l}\text { Premature } \\
\text { Full term } \\
\text { Difference }\end{array}$ & $\begin{array}{l}\ldots \\
\cdots \\
.\end{array}$ & $\begin{array}{r}7 \\
11\end{array}$ & $\begin{array}{l}4.91 \\
0.92 \\
3.99\end{array}$ & $\begin{array}{r}6 \\
12\end{array}$ & $\begin{array}{l}4 \cdot 07 \\
1 \cdot 67 \\
2 \cdot 40\end{array}$ & $\begin{array}{r}10 \\
5\end{array}$ & $\begin{array}{l}4 \cdot 84 \\
0 \cdot 99 \\
3 \cdot 85\end{array}$ \\
\hline $\begin{array}{l}\mathrm{t} \\
\mathrm{P}^{*}\end{array}$ & $\begin{array}{l}\cdots \\
\cdots\end{array}$ & & $\begin{array}{c}4 \cdot 63 \\
\text { less than } 0 \cdot 001\end{array}$ & & $\begin{array}{l}1.96 \\
\text { lies between } 0.1 \\
\text { and } 0.05\end{array}$ & & $\begin{array}{c}3.98 \\
\text { lies between } 0.01 \\
\text { and } 0.001\end{array}$ \\
\hline
\end{tabular}

\footnotetext{
- If the infant's crown-heel length is $l e s s$ than $50 \mathrm{~cm}$. it is considered premature.

$P$ is the probability that the full term and premature infants belong to the same group. When $P$ is less than 0.05 the groups were considered to differ significantly, when $P$ is less than $0 \cdot 10$ a suggestive difference was thought to exist.
}

premature by one criterion alone.) It follows that the main fall in haemopoietic activity occurred in the interval between the two groups, namely between the thirty-eighth and fortieth weeks of gestation.

None of the premature infants exceeded 38 weeks' gestation nor, when using both criteria, the corresponding crown-heel length of $48 \mathrm{~cm}$. Table 2 shows that there was no relationship between the amount of haemopoietic tissue and the degree of prematurity. Hence two groups showed no merging with respect to the number of haemopoietic foci in the liver. The difference between the premature and the full term foetuses was clear-cut. This is perhaps a little surprising in view of variability in the duration of pregnancy. Thus Karn (1947) has shown the mean duration to be 280 days with a standard deviation of $11 \cdot 3$ days.

Postmatal Recession. Following birth the changes in haemopoiesis showed two phases. During the first two or three days of life the number of foci did not diminish, and indeed in the first 12 hours they often increased, though the increase was not statistically significant. After this period the phase of decline set in and the haemopoiesis rapidly disappeared. The decline in haemopoiesis with respect to age can be represented by a logarithmic function. Fig. 2 shows the curve for the full term infants; those for the other groups of infants two to eight weeks premature and more than eight weeks premature were similar. The mean number of foci for each age group is also plotted on the graph.

After the first three days the fit between the calculated line and the mean was very good, although there was a fairly extensive variation about the mean. The fit was also good for the premature groups. This curve clearly shows the two phases in postnatal hepatic haemopoietic recession. In the first two or three days the number of foci present fell below the calculated curve, but with a tendency to increase just after birth.

The point at which the curve cut the axis of time gave the mean time of disappearance of haemopoietic tissue from the liver. In full term infants the mean time of disappearance was about eight days, in infants two to eight weeks premature about 18 days, and in infants more than eight weeks

TABLE 2

Comparison of the Amount of Hepatic Haemopoiesis with the Degree of Prematurtty, by Rank Correlation (KENDALL)

(a) By menstrual age

Case No. .

$\begin{array}{lllrrr}\text { Rank of menstrual age* } & \cdots & \cdots & 1 & 2 & 3 \\ \text { Rank of no. of haemopoietic foci } & \cdots & 1 & 7 & 6\end{array}$

$\begin{array}{rrr}282 & 385 & 588 \\ 3 & 4 & 5 \\ 6 & 2 & 4\end{array}$

$614 \quad 360$

6

Coefficient of rank correlation $=0$.

(b) By crown-heel length

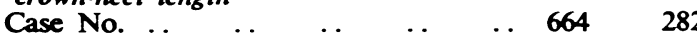

Rank of crown-heel length*

Rank of haemopoietic focit

Coefficient (not significant) of rank correlation $=0.015$.

$\begin{array}{rr}202 & 385 \\ 3 & 4 \\ 1 & 2 \\ \text { lation }= & 0 \cdot 015\end{array}$

$\begin{array}{rr}588 & 367 \\ 5 & 6 \\ 3 & 6\end{array}$

t In ascending order.

- In descending order. 


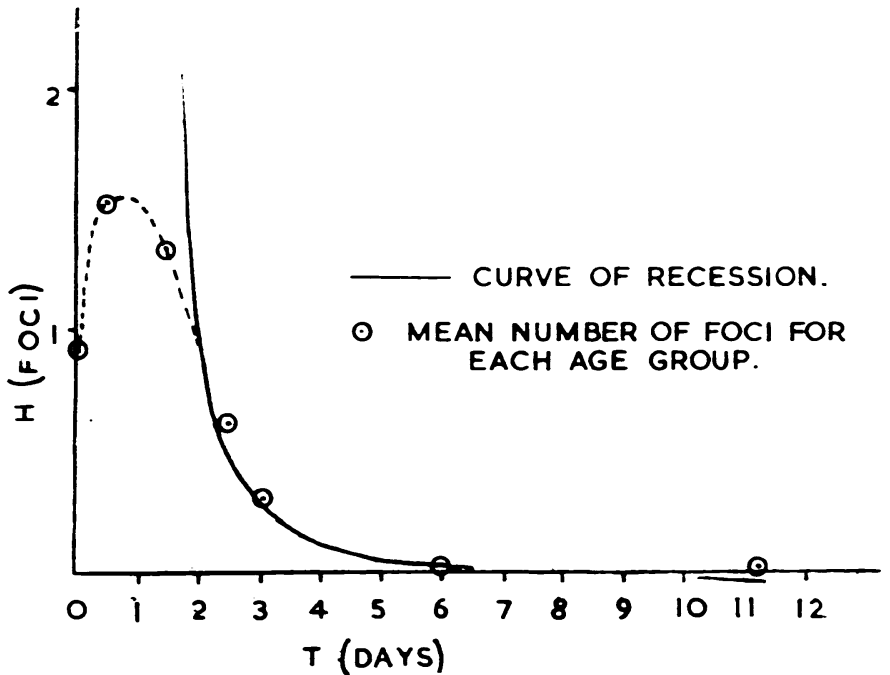

FIG. 2.-This shows the diminution in hepatic haemopoietic tissue with age at death $(T)$, in the group of full term infants. Haemopoietic tissue is measured by the average number $(\mathrm{H})$ of haemopoietic foci present in $\mathbf{1 0 0}$ high power fields. The postnatal increase in haemopoiesis is clearly shown and the close agreement of observations, after the first three days, with the calculated curve of recession is evident.

premature about 38 days. It follows that haemopoietic foci disappeared from the liver sooner in full term than in premature infants, and the more premature the infant the longer the foci persisted, although in diminishing numbers. It may be that the duration of these haemopoietic foci depended on the initial level of haemopoiesis at birth. Since, however, there was no relationship, in the range considered, between the degree of prematurity and the level of haemopoiesis in stillborn infants such a hypothesis remains speculative.

The haemopoietic foci lay in the liver sinusoids or in lacunae off them and also in the connective tissue of the smaller portal tracts. There was no evidence that the sinusoidal foci disappeared at a different rate from those in the portal tracts. No attempt was made to follow the changes qualitatively. When the foci were small and scanty the nuclei of the cells were highly pyknotic and some - showed karyorrhexis. The cells were then difficult to distinguish from polymorphic leucocytes.

Two Types of Haemopoietic Recession. In Table 3 the mean time of disappearance of hepatic haemopoiesis in premature infants is compared with the mean time at which haemopoiesis would have been expected to disappear had the infant been - born at full term. It follows that in infants two to eight weeks premature haemopoiesis disappeared on an average 17 days before the expected date of delivery, and in infants more than eight weeks premature it disappeared about 36 days before the expected date of delivery. In contrast, all of the full term infants, who were stillborn or survived up to two days ( 23 infants in all), had haemopoietic foci in the liver. It follows that in premature infants hepatic haemopoiesis recedes more rapidly after birth than if the infants continued to live in utero.

It was shown above, when considering the stillborn infants alone, that hepatic haemopoiesis diminishes in the last two weeks or so before birth. Hence two types of recession can be distinguished: (a) an intra-uterine type, and (b) an extra-uterine type, and the one process is not a simple continuation of the other.

In premature infants one or two rows of incompletely developed glomeruli may be seen beneath the capsule of the kidney; at term few infants have such immature glomeruli,and the extent of this immaturity is a useful guide in routine pathology to the degree of prematurity. This phenomenon has been extensively studied by Potter and Thierstein (1943). I found that postnatal maturation of the glomeruli of premature infants occurred at about the same time as if the infants had remained in utero. This is in contrast to the hastening of the haemopoietic recession which occurred in the same infants after birth.

TABLE 3

Degref of Prematurity Compared with the Mean Age OF Disappearance OF HaEmopoletic Foci from THE LIVER

\begin{tabular}{|c|c|c|c|}
\hline $\begin{array}{l}\text { Degree of } \\
\text { Prematurity }\end{array}$ & $\begin{array}{l}\text { Full } \\
\text { Term }\end{array}$ & $\begin{array}{l}\text { 2-8 Weeks } \\
\text { Premature }\end{array}$ & $\begin{array}{l}\text { More than } \\
8 \text { Weeks } \\
\text { Premature }\end{array}$ \\
\hline $\begin{array}{ccc}\text { Mean degree } & \text { of } & \text { pre- } \\
\text { maturity } & . . & .\end{array}$ & 0 & $35 \cdot 0$ days & $73 \cdot 5$ days \\
\hline $\begin{array}{l}\text { Mean age when haemo- } \\
\text { poiesis disappears }\end{array}$ & $8 \cdot 0$ & $18 \cdot 0$ days & $37 \cdot 6$ days \\
\hline Comparison & - & $17 \cdot 0$ days & $35 \cdot 9$ days \\
\hline
\end{tabular}

Time of Disappearance of Hepatic Haemopoietic Tissue. One of the objects of this investigation was to determine the time at which haemopoietic tissue disappeared from the liver. This clearly varied with the degree of prematurity and with the individual. 
Hence the mean time of disappearance was an inadequate measure but, theoretically, limits could be set between which haemopoietic tissue would have disappeared in $95 \%$ of individuals. The method used was based on the work of Schultz (1930) using a formula of Snedecor (1946). The family of curves which represented the second phase of postnatal haemopoietic recession was given by the equation $\log _{e}(H+0.01)=a+b \log _{e} T$. The $95 \%$ range for the time of disappearance of haemopoietic tissue is given in Table 4. Unfortunately the upper limit of this range was indeterminate for premature infants, probably due to inadequate data. This method of determining the range may seem a little artificial since the logarithmic formula is strictly a mathematical fiction. However, the conclusions drawn from the formula agreed with the observations. Thus of (a) full term infants, the first to show no foci was $3 \frac{1}{2}$ days old and the last 13 days old; (b) of infants two to eight weeks premature, the first to show no foci was 8 days old and the last 21 days old; (c) of infants more than eight weeks premature, the first to show no foci was 2 weeks old but the range was not long enough to give the final figure.

TABLE 4

95\% RANGe for the Mean Time OF Disappearance of HAEMOPOIETIC FoCI

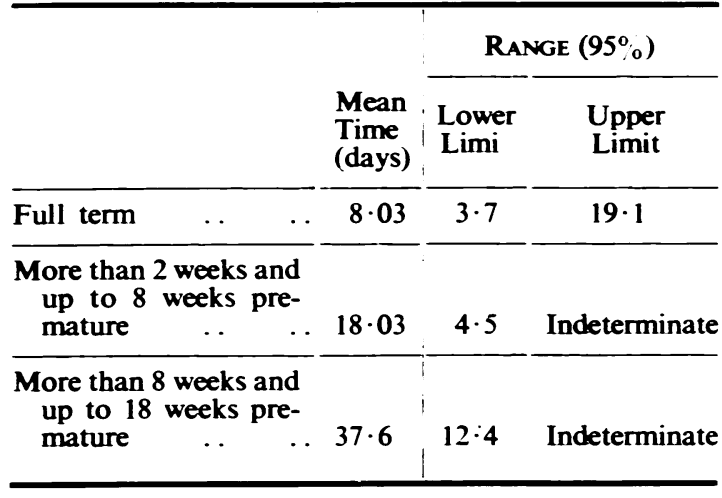

The Accumulation of Iron Pigment

Visible Iron in the Liver and Spleen of Stillborn Infants. Sections of tissue from 18 stillborn infants were studied. In nine infants there was a positive iron reaction in the liver and in six of these the reaction was also positive in the spleen. In one infant (S.369) iron was visible in the spleen but not in the liver. Statistical analysis showed no relationship between the presence or absence of visible iron in the liver and (a) the prematurity of the infant, or $(b)$ the amount of hepatic haemopoietic tissue.
Rebationship between Age and Visible Iron in the Liver. Fig. 3 shows the mean grade of visible iron in each age group plotted against the age at death. In both full-term and premature infants there was a fall in the visible iron content in the age range of 1 to 3 days, after which there was an almost progressive rise for 3 to 4 weeks, followed by a fall after about 3 months. Infants who were more than eight weeks premature were not included in the graph because the group was small and the individual variations so great that they upset the visual trend. However, all infants are included in Table 5. It can be seen that there was a higher

TABLE 5

Frequency of Hepatic Siderosis in Full Term and Premature INFANTS

\begin{tabular}{|c|c|c|c|}
\hline Age at Death & & $\begin{array}{l}\text { No. of } \\
\text { Infants }\end{array}$ & $\begin{array}{l}\text { No. with } \\
\text { Siderosis }\end{array}$ \\
\hline Stillborn & . & 18 & 9 \\
\hline Less than 1 day & . & 17 & 12 \\
\hline $1<3$ days $\ldots$ & . & 10 & 3 \\
\hline $3<8$ days $\ldots$ & . & 16 & 11 \\
\hline $8<15$ days $\ldots$ & $\cdots$ & 9 & 6 \\
\hline $15<28$ days. & . & 7 & 6 \\
\hline $1<2$ months & . & 8 & 8 \\
\hline 2 to 7 months & $\cdots$ & 7 & 6 \\
\hline Total & . & 92 & 61 \\
\hline
\end{tabular}

proportion of infants without visible iron in the liver dying between one and three days than at any other period, and that after this the proportion of cases showing no iron rapidly diminished. There was much more individual variation with regard to visible iron than haemopoiesis. In all age groups, except the 1-2 months group, some livers gave a negative reaction for iron.

The fall in the visible iron (Fig. 3 and Table 5) in the early days of life was not statistically significant. It is interesting to note that the fall occurred one to two days later than the probable rise in haemopoiesis (Fig. 2). Although neither of those changes, taken separately, was significant they might have been when taken together. Unfortunately I know of no convenient test for combining them.

Comparison of Quantities of Haemopoietic Tissue and Visible Iron in the Liver. From Table 6 it can be seen that whereas siderosis was frequently associated with the presence of haemopoiesis it was 


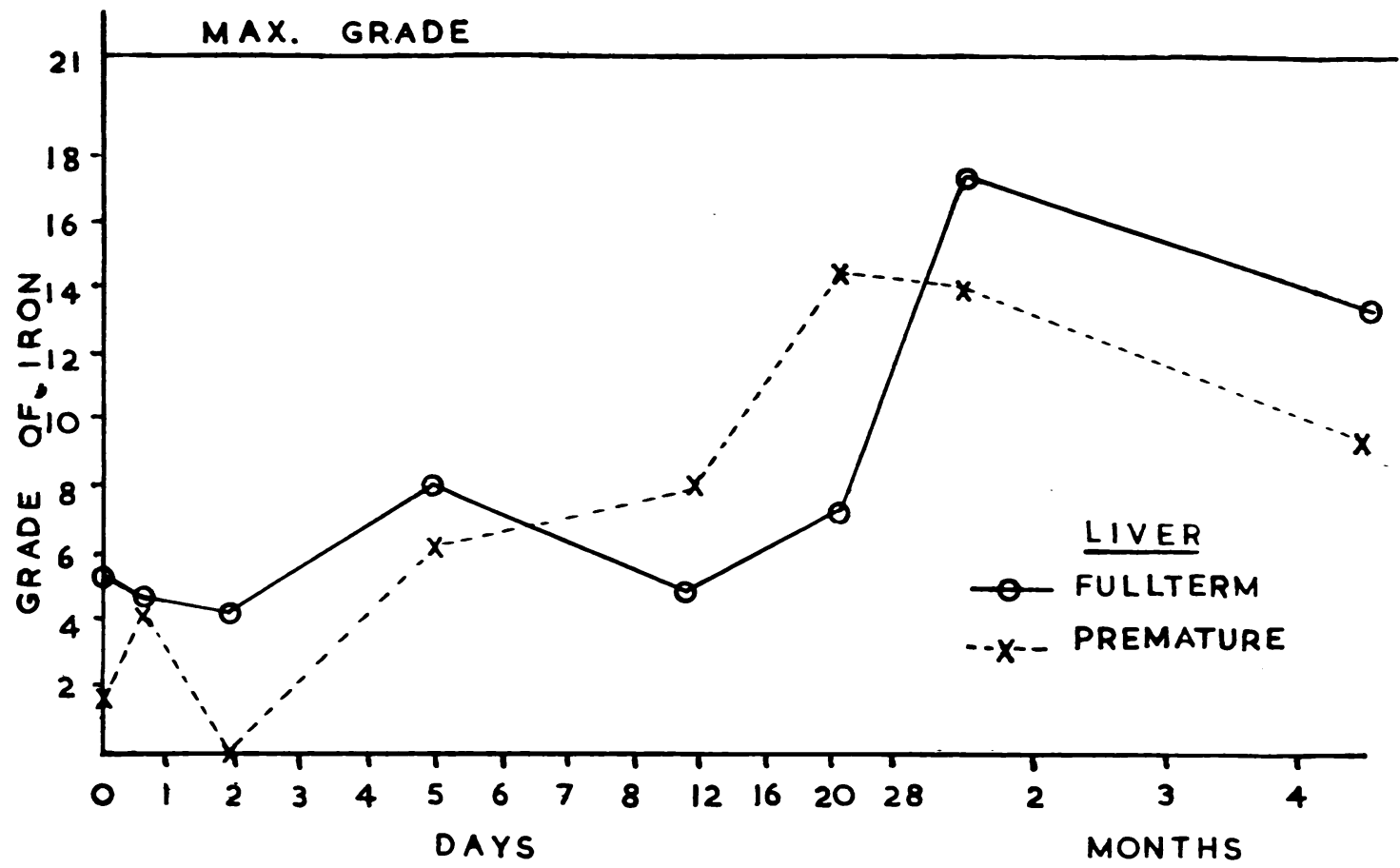

Fig. 3.

more frequently associated with its absence. The difference is statistically significant. Analysis of the data with regard to prematurity or other factors yields no further information.

TABLE 6

Frequency of Haemopoiesis and Siderosis in the LIVER COMPARED

No. with No. without Haemopoiesis Haemopoiesis Total

\begin{tabular}{|c|c|c|c|}
\hline Siderosis present & 34 & 27 & 61 \\
\hline Siderosis absent & 25 & 4 & 29 \\
\hline Total & 59 & 31 & 90 \\
\hline
\end{tabular}

$\chi^{2}$ (using Yates' correction) is 6.86 hence the distribution could occur by chance (Fisher and Yates, 1948) less than once in 200 times.

Distribution of Visible Iron in the Liver. Iron pigment was present in the liver cells, or in the cells in the sinuses, or usually in both. In only one infant (S.605) was the pigment present in the sinus cells and not in the parenchymal cells. The distribution of iron between sinuses and parenchyma bore no relation to the amount of pigment present or the age of the infant. In the liver cells the pigment was usually present as diffusely scattered granules but occasionally it was most marked near the bile canaliculi. Sometimes iron was visible in all the liver cells but, at others, it was concentrated in the cells near the portal tracts. Occasionally it was near the centrilobular veins. The distribution in the parenchyma bore no relationship to the amount of pigment present. Iron was found in the portal tracts themselves in only two livers, and then in very small amounts, which contrasts with some of my cases of haemolytic disease of the newly born in which this was a conspicuous feature. In the sinuses pigment was most often found in the Kupffer cells, but in nine livers it was also found in cells about the size of a red blood corpuscle. The nature of these cells was not determined. In the sinuses the pigment gave a diffuse coloration to the cells in contrast to the granular appearance of the liver.

Relationship between Age and Visible Iron in the Spleen. In Fig. 4 the mean grade of visible iron in the spleen in each age group is plotted against the age at death, and in Table 7 the number of spleens which contained iron in each age group are given. In the first few days after birth there was a fall in the mean amount of visible iron and in the frequency with which it was present. This fall was most marked in the age range 1 to 3 days. After this 


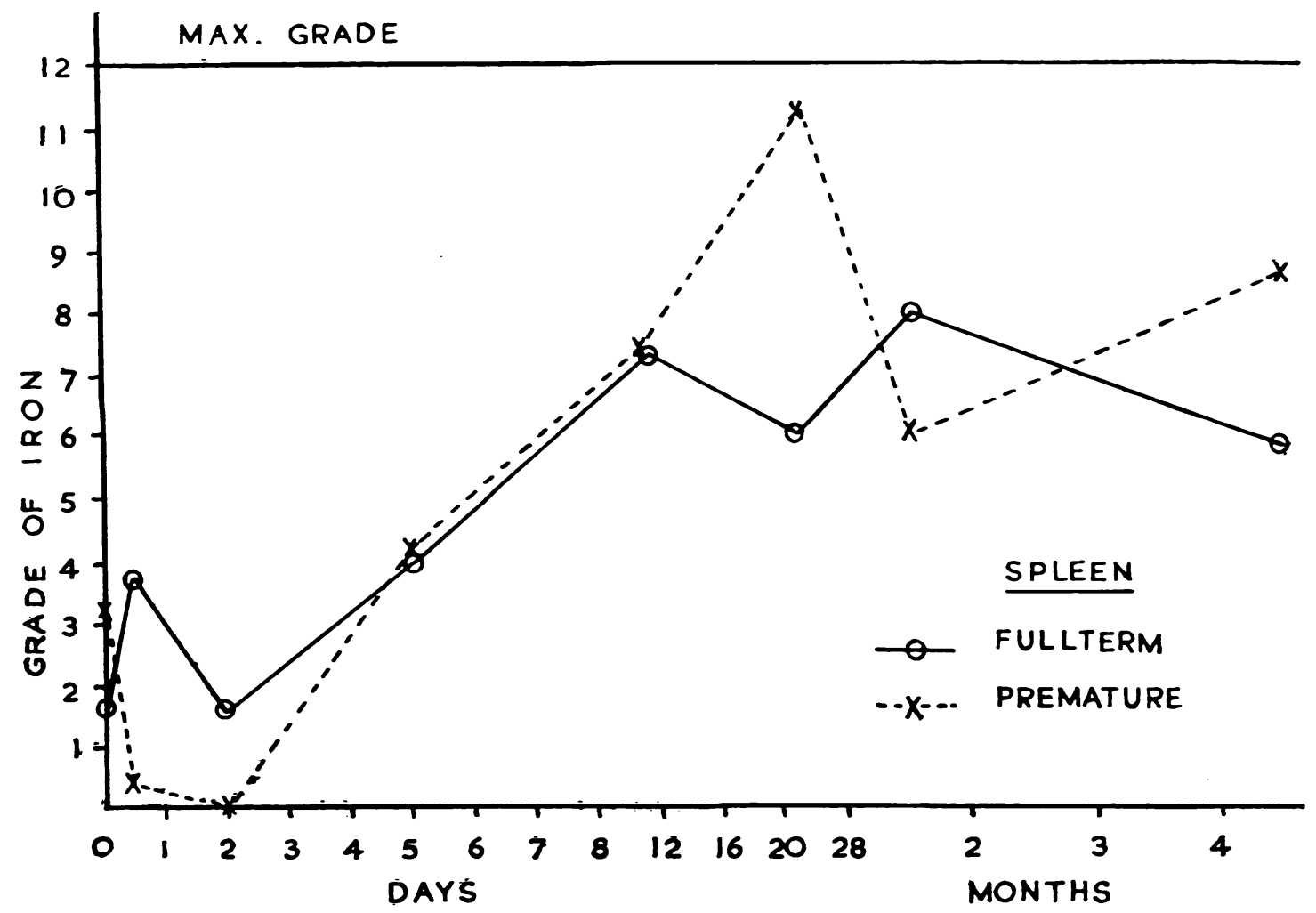

Fig. 4.

period the amount of iron progressively rose for one to two weeks and then varied about a maximum, but occasionally a spleen was found which showed no pigment. On inspection, there was no significant

TABLE 7

Frequency of Splenic Siderosis in Full Term and Premature Infants

\begin{tabular}{|c|c|c|}
\hline Age at Death & $\begin{array}{l}\text { No. of } \\
\text { Infants }\end{array}$ & $\begin{array}{l}\text { No. with } \\
\text { Siderosis }\end{array}$ \\
\hline Stillborn & 18 & 7 \\
\hline Less than 1 day & 15 & 5 \\
\hline $1<3$ days $\ldots$ & 9 & 1 \\
\hline $3<8$ days $\ldots$ & 11 & 6 \\
\hline $8<15$ days $\ldots$ & 8 & 8 \\
\hline $15<28$ days. & 6 & 5 \\
\hline 1 to 7 months & 10 & 7 \\
\hline Total & 77 & 39 \\
\hline
\end{tabular}

difference between the premature and full term group. The similarity in behaviour between the liver and the spleen was marked. The only easily detectable difference was that the maximum accumulation of iron occurred perhaps a little later in liver than in the spleen of full term infants, but this difference was not present in premature infants.

Distribution of Iron in the Spleen. The siderotic granules were intracellular and were only present in the pulp, either in cells lining the sinuses or lying free in the sinuses. Neither the follicles nor the connective tissue of the capsule and trabeculae gave a positive prussian blue reaction. In haemolytic disease of the newly born the connective tissue frequently gives a positive iron reaction.

Correlation between Grades of Iron in the Liver and Spleen. The correlation coefficient was 0.555 and was statistically significant. This positive correlation, although rather low, is in conformity with the parallelism between the graphs showing the accumulation of the pigment with time (Figs. 3 and 4, and Tables 5 and 7).

Renal Siderosis. The kidneys of almost all these infants were examined. In only two cases was there 
evidence of siderosis and in both it was very faint. This was in marked contrast to my series of infants with haemolytic disease of the newly born in which renal siderosis was conspicuous.

\section{Results}

The analysis may be summarized as follows:

(1) Hepatic haemopoiesis diminished in the later part of intra-uterine life, particularly in the last two weeks before the expected date of birth.

(2) In postnatal life haemopoietic tissue in the liver diminished after the second or third day of life. The process approximately followed a logarithmic law. Haemopoietic tissue persisted longer the more premature the infant.

(3) Although hepatic haemopoiesis receded in the last few weeks of gestation this process was hastened by premature birth. In contrast, renal maturation was not hastened by premature birth.

(4) Iron pigment was found in the livers of half the stillborn infants and in the spleens of over one-third of them.

(5) Infants dying from one to three days after birth often had less visible iron in the liver and spleen than those dying earlier. After three days the visible iron rose progressively in amount for about two weeks to a maximum value at which it remained for several months.

(6) Siderosis was present in over two-thirds of the livers, and although frequently associated with the presence of haemopoiesis, occurred more often in its absence. The degree of siderosis in the liver and spleen was fairly closely correlated. In the liver the distribution of iron pigment bore no relationship to the amount. There was some . evidence that hepatic haemopoietic tissue increased slightly in the first few hours after birth; likewise one to three days after birth hepatic and splenic siderosis decreased.

\section{Discussion}

Hepatic Haemopoiesis in relation to the Postmatal Fall in the Erythrocyte Count. In late foetal life and just after birth the circulating red cells in man are derived from two sources, the liver and the bone marrow. Since hepatic haemopoiesis is diminishing, the number of erythrocytes entering the circulation from the liver will fall and, after a time lag depending upon the life span of these cells, the fall in erythrocytes will be reflected in the red cell count of the circulating blood. Thus diminution of hepatic haemopoiesis is one of the factors contributing to the fall in the red cell count in early neonatal life. The importance of this factor cannot be estimated properly until we can distinguish between the red cells produced by the liver and those produced by the bone marrow.

Grüneberg $(1942,1947)$ in his study of the anaemia of flexed-tail mice has shown that three types of red cell, which succed each other during development, can be distinguished. In the mouse and the rat primitive red cells which are large (about $12 \mu$ in diameter) and mostly nucleated are produced in the yolk sac. These are followed by smaller cells, about $8 \mu$ in diameter, mostly non-nucleated and produced by the liver and spleen; these are intermediate cells which dominate the blood picture in the last third of pregnancy. At about the time of birth a fresh generation of red cells appears (about $6 \mu$ in diameter) and this is the definitive generation produced by the bone marrow. Thus, if human haemopoiesis exhibits three generations, as in the mouse and the rat, it seems possible that the erythrocytes arising in the liver differ in size from those arising in the marrow. Findlay (1946) has shown that the mean corpuscular volume is much greater in the foetus of 34 to 42 weeks' maturity than in the newborn, the fall occurring soon after birth, so that after an age of 15 days no infant's mean cell volume exceeds $100 \mu^{3}$. Similarly van Creveld (1932) has shown that the mean cell diameter of both full term and premature infants falls in the first six weeks following birth. These changes in cell size parallel the postnatal fall in the circulating red cell count (Findlay, 1946) and can readily be explained if the larger cells are derived from the liver and the smaller ones from the bone marrow since, as the larger cells reach the ends of their life spans, they will not be replaced by the atrophic hepatic system. Moreover, the simultaneous presence of two generations of red cells distinguished by size accounts for the anisocytosis present at birth but diminishing in the first six weeks of life (van Creveld, 1932; Smith, 1945).

Barcroft (1946) has suggested that the diminution in cell size is accompanied by a substitution of adult for embryonic foetal haemoglobin. If this is true it may be that the large hepatic erythrocytes contain foetal haemogiobin and the smaller erythrocytes of bone marrow the adult type. On the other hand the cells may contain a mixture of the two haemoglobins (Brinkman, Wildschut, and Wittermans, 1934). Likewise, the change in red cell fragility between the foetal and neonatal period may be due to differing properties of the two generations of cells. Thus Findlay (1945) found that the blood of the foetus shows a diminished resistance, but in the newborn child the resistance is increased.

Mollison's (1948) observations on the survival of placental blood transfused into newborn babies support this concept of heterogeneity of neonatal 
blood. He showed that for about ten days after transfusion the donated cells disappeared more rapidly than cells of an adult donor; after ten days the rate of disappearance of placental and adult cells was the same. He concluded that a small proportion of the infantile cells disappeared more rapidly than adult erythrocytes. It would be interesting to know if the larger erythrocytes have the shorter life span.

The postnatal fall in the red cell count and haemoglobin concentration is usually attributed to excessive haemolysis following birth (Parsons, 1933; Smith, 1945). This has been denied by Findlay (1946) and a diminished rate of formation suggested by Josephs (1932). One of the main difficulties in accepting this theory of excessive haemolysis is that no adequate mechanism has been suggested. Davidson et al. (1941) write : 'The excessive destruction of erythrocytes which characterized the neonatal period appears to be caused by release from foetal anoxaemia.' A similar view was expressed by Wollstein (1938) who also explained the siderosis of the liver and spleen as a result of the iron freed by destruction of haemoglobin. It is a curious idea that a full oxygenation of blood in vivo should result in excessive haemolysis; there is no in vitro evidence to suggest such a possibility. Fallon (1943), without citing her evidence, attributes the postnatal fall in erythrocytes to increased phagocytosis of the red blood corpuscles consequent on increased oxygen supply at birth. Mitchell (1928) reported the presence of haemolysin in the maternal serum which can affect cord blood, but this could not be confirmed by Goldbloom and Gottlieb (1930). Engelhardt (1947) has suggested that the postnatal haemolytic mechanism is similar to that of a normal adult. The agent is lysolecithin, which is found in the blood of the newborn in comparatively large amounts. The action of lysolecithin is inhibited in the first few days of life by oestrone and as this falls there is an increase in cholesterol. The rise in the cholesterol level is not enough to check blood destruction owing to a simultaneous rise in lecithin. This theory needs critical examination and replication of its experimental basis before it can be accepted.

The evidence in favour of excessive haemolysis is based on (a) the occurrence of siderosis of the liver and spleen in the neonatal period, $(b)$ the development of bilirubinaemia, and (c) certain experimental evidence.

Siderosis of the Liver, Spleen, and Kidney. Brückmann and Zondek (1939) have reviewed the life curves of iron in the liver and kidney which have been reported by various workers. Ramage et al. (1933) using spectrographic methods showed that the average iron content of human foetal livers in the first 24 weeks of gestation is $0.21 \%$ of dry weight, at full term is $0 \cdot 25 \%$, rising to a maximum of $0.374 \%$ at one to two months after birth, falling to a minimum of $0.048 \%$ at 13 to 24 months. Barcroft (1946) has criticized these results on the grounds that Ramage and his colleagues did not exclude the blood that was in the vessels in their estimations. Barcroft (1946) quotes figures obtained by McDougall on foetal sheep and lambs in which blood was removed from liver slices by washing: these show marked variation in iron content, even between the livers of twins, but there is a general tendency to rise in the second half of pregnancy. Brückmann and Zondek (1939) using a method of estimating non-haemin iron have shown that the iron content of the liver is high in the first two weeks of life averaging $0 \cdot 177^{\circ} \%$ of dry weight (range 0.030 to $0 \cdot 290 \%$ ) falling to a minimum average value of $0.017 \%$ at the age of 2 years, after which it rises slowly so that at the age of 20 years the adult level of $0.08^{\circ} \%$ is reached. A similar life curve occurs in the kidney, but at a lower level, the average iron content in the first few days of life being $0.0205^{\circ}, \ldots$. These results are similar to those of Ramage et al. (1933), but at a lower level, since only non-haemin iron is measured, and conform in a general way with my histological findings.

Brückmann and Zondek (1939) write:

- The values in the newborn are in general quite high, but there are exceptions. According to the classical theory ... . the newborn has a congenital reserve deposit of non-haemin-Fe, which is to compensate for the lack of Fe in the milk diet of the first few months. But a series of investigations indicates that this is true only in part ... Some increase in non-haemin-Fe occurs already during foetal life, but the bulk of it is not accumulated until after birth, when the well-known postnatal blood destruction reduces the high haemoglobin values to about $50 \%$ within a few weeks, liberating large amounts of Fe.'

An alternative hypothesis is that the high iron content of the foetal liver is not a store laid by for the future suckling phase but a supply immediately available for the present demands of hepatic erythropoiesis. As haemopoiesis diminishes in late foetal life and in the early neonatal period the hepatic iron is less rapidly utilized and therefore accumulates in the liver cells, ultimately reaching a level at which the particles are large enough to be visible when stained by the prussian-blue method. Alongside this process it may be supposed that when the hepatic iron reaches a sufficiently high level and is not used for erythropoiesis, some is drained off and deposited in the spleen. Moreover, if the usual view is taken that siderosis represents excessive haemolysis it is difficult to account for the fact that 
nine out of 18 of my stillborn infants showed hepatic siderosis, and Gilmour (1941) found siderosis in younger foetuses.

Gillman and Gillman (1945) have shown that in haemolytic conditions iron appears first in the Kupffer cells and only later in the hepatic cells. In contrast Waterlow (1948) pointed out that in pernicious anaemia iron is mainly present in the parenchyma, and he considers this a condition in which utilization is prevented by lack of liver principle. The bulk of the iron in my cases was probably in the liver cells, but often the Kupffer cells were well filled, and in one liver the iron was almost entirely in the Kupffer cells. Thus the distribution of iron gives no simple explanation of the mechanism of siderosis in the foetus and newly born infant.

Neonatal Hyperbilirubinamia. The rise in the bilirubin content of the blood and the resulting physiological jaundice are usually attributed to neonatal haemolysis (Wollstein, 1938). However, as Findlay, Higgins, and Stanier (1947) have pointed out, whereas bilirubinaemia usually reaches its maximum in the first week of life and thereafter decreases, the fall in the erythrocyte count and haemoglobin content are greater in the second week when the bilirubin level is falling; moreover, the rate of fall in the erythrocyte count and haemogiobin is the same in the icteric group of infants as in the non-icteric. They concluded that excessive haemolysis is not the cause of icterus neonatorum. During intra-uterine life bilirubin may be removed from the foetus by means of the placenta and by excretion through the liver. Ÿlppö (1913) denied that foetal bilirubin is normally excreted by the placenta since the maternal plasma bilirubin level is not raised during pregnancy. Findlay et al. (1947) pointed out that the amount produced by the foetus each day is so small that it could not appreciably affect the maternal blood level. Moreover it has been shown that the bilirubin level in the umbilical artery of newborn babies is higher than in the umbilical veins (Cserna and Liebmann, 1923; Findlay et al., 1947). At birth the placental excretion is suddenly cut off and the burden thrown on the liver. Thus, unless the excretory capacity of the liver is sufficient, the blood bilirubin level may be expected to rise. Davidson et al. (1941) analysed Ÿlppö's data and showed that the less the bilirubin content of the first meconium the greater the intensity of the subsequent icterus. Similarly, Findlay et al. (1947) have re-examined Yilppö's data and showed that the greater the bile content of the faeces during the first five days of life the less the jaundice. They give data collected by themselves indicating that the more severely jaundiced babies excreted less bilirubin in the faeces than the less jaundiced. Both these groups of workers concluded that the degree of neonatal bilirubinaemia is a function of the maturity of the liver. Further, Findlay et al. (1947) showed that the more premature the infant the more likely it was to develop jaundice, which may reasonably be expected if maturity of liver function is an important factor.

Experimental Observations. Goldbloom and Gottlieb (1930) kept guinea-pigs in a chamber under reduced pressure for about one month. The haemoglobin and red cells increased as in acclimatization to high altitudes. When the animals were returned to normal atmospheric conditions the haemoglobin and the red cell level fell to normal in about five days and the icteric index immediately rose. Conditions in the chamber were supposed to correspond to those in utero and removal from the chamber be analogous to birth. Thus the fall in haemoglobin and erythrocyte count and the rise in the icteric index appeared to correspond to the changes in neonatal life. Examination of their protocols shows that in three of their 11 experiments the bilirubin was raised before the animal left the chamber, and in the others the maximum bilirubin level was reached immediately after removal from the chamber and then fell. These did not therefore correspond to the findings in neonatal life. It may be that the period of reduced pressure corresponded to the life span of guinea-pig erythrocytes, in which case an increased breakdown would have occurred near the end of the period of exposure. Findlay et al. (1947) suggested that anoxaemia might have caused liver inefficiency. Further, the conditions in the chamber were not those of intra-uterine life, especially with regard to the blood carbon dioxide level (Barcroft, 1946).

Dymamic Haematology. From this discussion it may be concluded that there is no direct evidence of excessive haemolysis occurring soon after birth and that all the indirect evidence is capable of an alternative, or better, explanation. Until the changes in the infant's blood are analysed in terms of dynamic haematology, as attempted by Grüneberg (1942) for the anaemia of flexed-tail mice, we shall not know what part, if any, is played by excessive postnatal haemolysis. To make such an analysis it will be necessary to know $(a)$ the changes in blood volume at birth, (b) the rates of production and wastage of both the hepatic and marrow erythrocytes, (c) the constancy, or otherwise, of the mean cell size of the two generations of erythrocytes. It must also be remembered that the infant is growing and that newly formed erythrocytes not only replace loss by normal wastage but add to the size of the circulating erythron. A number of these factors 
have been studied, e.g., the growth of the circulating erythron (Findlay, 1946) and blood volume (Lucas and Dearing, 1921; Smith, 1945; Grüneberg, 1941) but such information is not sufficiently extensive for an adequate analysis.

Mechanism of Haemopoietic Recession in the Liver. Any discussion of this mechanism is at present speculative. It may be that in foetal life haemopoietic activity is maintained at a high level by anoxaemia, as in adaptation to high altitudes, but the higher carbon dioxide content and tension of foetal blood may play a part. With the onset of pulmonary respiration at birth the oxygenation of the blood rises and thus the stimulus to proliferation of the hepatic haemopoietic system falls. The recession of haemopoiesis in the last few weeks of gestation is not an isolated phenomenon. It is at this time that subcapsular development of new glomeruli ceases; the pregnanediol and oestrone excretion starts to decline and shows violent fluctuations (Hain, 1942), and in animals there is a rapid accumulation of glycogen in the liver (Needham, 1931; Schlossmann, 1938; Windle, 1940).

Siderosis in Malnutrition. Helmholz (1909), Lubarsch (1921), and Saito (1924) have described siderosis of the liver and spleen in infants dying in a state of malnutrition. Waterlow (1948) described siderosis and found the non-haemin iron content raised in the liver and spleen of infants dying in the West Indies of undernutrition and 'fatty liver disease'. He ascribed these changes to failure to utilize iron since he could find no evidence of haemolysis, the bilirubin content of the blood being raised only in the presence of liver damage. The distribution of the siderosis was similar to that I have described. Waterlow's results show the same trend as those of Brückmann and Zondek (1939), namely a fall in non-haemin iron in the liver with increasing age, but his results are all much higher than those (which he uses as controls) of Brückmann and Zondek. His observations would have been more convincing had he run a series of controls of his own for comparison. Andersen (1938) found siderosis of the liver in 14 of 19 infants dying of cystic fibrosis of the pancreas before the age of 6 months; after the age of 6 months the incidence diminished. The infants I have described showed marked siderosis of the liver and spleen with a slight tendency to diminish between the ages of 4 and 7 months, and this was a continuation of foetal and neonatal siderosis. It seems probable that the siderosis of infants which is ascribed to malnutrition is really a physiological process.

Summary

There are two types of hepatic haemopoietic recession: (a) an intra-uterine type, most marked in the last weeks before birth, and (b) an extrauterine type which succeeded birth after a lag period of one to three days.

Extra-uterine atrophy followed an approximately logarithmic law.

The mean time of disappearance of haemopoietic tissue from the liver of full term infants was about eight days after birth, and for infants born eight to 13 weeks premature $37 \cdot 6$ days.

Siderosis of the liver and spleen was present in both foetuses and infants born alive. After the first three days of life the degree of siderosis rose progressively to a maximum in about two weeks; it remained at this level for some months.

The literature contains no well-established evidence that the postnatal fall in the erythrocytes count is due to excessive haemolysis.

The evidence given here suggests that the postnatal fall in the erythrocyte count is, in part, due to atrophy of erythropoietic tissue in the liver.

Evidence from the literature suggests that the cells produced by hepatic erythropoiesis have different properties, such as size and life span, from those derived from bone marrow.

In the foetus and newly born infant iron brought to the liver is used in haemopoiesis. When haemopoiesis diminishes after birth the iron accumulates giving rise to siderosis. Some of the excess iron is probably removed and deposited in the spleen.

Siderosis described in infants dying of malnutrition is probably of no pathological significance.

I wish to thank Professor Baker and Professor Morris, in whose departments this work was done, for their help and advice, and Dr. R. Whitehead for his criticism of the text.

\section{REFERENCES}

Andersen, D. H. (1938). Amer. J. Dis. Child., 56, 344. Barcroft, J. (1946). 'Researches on Pre-natal Life, Vol. 1. Oxford.

Brinkman, R., Wildschut, A., and Wittermans, A. (1934). J. Physiol., Lond., 80, 377.

Brückmann, G., and Zondek, S. G. (1939). Biochem. J., $33,1845$.

Creveld, S. van (1932). Amer. J. Dis. Child., 44, 701.

Cserna, S., and Liebmann, S. (1923). Klin. Wschr., 2, 2122.

Davidson, L. T., Merritt, K. K., and Weech, A. A. (1941). Amer. J. Dis. Child., 61, 958.

Engelhardt, J. (1947). Maandschr. Kindergeneesk., 15, 267.

Fallon, M. (1943). J. Pediat., 23, 721.

Findlay, L. (1945). Archives of Disease in Childhood, 20, 64.

(1946). Ibid., 21, 195.

—, Higgins, G., and Stanier, M. W. (1947). Ibid., $22,65$.

Fisher, R. A., and Yates, F. (1948). 'Statistical Tables for Biological, Agricultural and Medical Research,' 3rd ed. Edinburgh. 
Gillman, J., and Gillman, T. (1945). Arch. Path., 40, Ramage, H., Sheldon, J. H., and Sheldon, W. (1933). 239.

Gilmour, J. R. (1941). J. Path. Bact., 52, 25. (1944). Archives of Disease in Childhood, 19, 1.

Goldbloom, A., and Gottlieb, R. (1930). J. clin. Invest., 8, 375 .

Gömöri, G. (1936). Amer. J. Path., 12, 655. (1937). Ibid., 13, 993.

Grüneberg, H. (1941). J. Path. Bact., 52, 323.

- (1942). J. Genet., 43, 45.

- (1947). 'Animal Genetics and Medicine,' p. 146. Hamilton, London.

Hain, A. M. (1942). J. Endocrinol., 3, 10.

Helmholz, H. F. (1909). Jb. Kinderheilk., 70, 458.

Josephs, H. (1932). Amer. J. Dis. Child., 43, 1035.

Karn, M. N. (1947). Ann. Eugen., Camb., 14, 44.

Lucas, W. P., and Dearing, B. F. (1921). Amer. J. Dis. Child., 21, 96.

Lubarsch, O. (1921). Beitr. path. Anat., 69, 242.

McDougall, E. I. (1946). See Barcroft (1946), p. 87.

Mitchell, J. M. (1928). Amer. J. Dis. Child., 36, 486.

Mollison, P. L. (1948). Lancet, 1, 513.

Needham, J. (1931). ' Chemical Embryology.' Cambridge.

Parsons, L. G. (1933). Archives of Disease in Childhood, $8,85$.

Potter, E. L., and Adair, F. L. (1940). ' Fetal and Neonatal Death.' Univ. Chicago Press, Illinois.

- and Thierstein, S. T. (1943). J. Pediat., 22, 695.

Saito, H. (1924). Virchow's Arch., 250, 69.

Schlossmann, H. (1938). J. Physiol., Lond., 92, 219.

Schultz, H. (1930). J. Amer. statist. Ass., 25, 139.

Smith, C. A. (1945). 'The Physiology of the Newborn Infant.' Springfield, Illinois.

Snedecor, G. W. (1946). ' Statistical Methods Applied to Experiments in Agriculture and Biology,' 4th ed. Collegiate Press, Iowa.

Waterlow, J. C. (1948). Spec. Rep. Ser. med. Res. Coun., No. 263.

Windle, W. F. (1940). 'Physiology of the Fetus.' London.

Wollstein, M. (1938). 'Handbook of Haematology' ed. Downey, H., Vol. 2, p. 925. New York.

Ylppö, A. (1913). Z. Kinderheilk., 9, 208. 